\title{
Juventude, intelectualidade e política: a ativação do "legado" de André Forster e a consagração de uma geração
}

ELIANA DOS REIS*

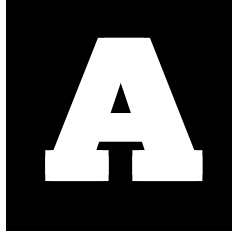

temática central do artigo ora proposto se insere no campo de discussões sobre o potencial heurístico das noções de "geração" e "memória" para a compreensão de um momento histórico específico e os atores de sua produção. Para tanto, toma-se como universo empírico um conjunto de agentes que estiveram engajados na "luta contra a ditadura" nos anos 60 e 70 no Rio Grande do Sul. A partir das narrativas oferecidas por estes ex-jovens militantes de esquerda sobre o passado, tendo como foco a atuação política de André Cecil Forster, ${ }^{1}$ busca-se apreender os usos de determinadas categorias identitárias, bem como a operação de memória ativada para tal.

Deste modo, a unidade entre as duas dimensões, engajamento na luta contra a ditadura e geração, reside na possibilidade de compreender o acontecimento histórico e a atuação dos atores, aliados às identificações e problemáticas aí forjadas. Isto é, observam-se simultaneamente as condições históricas, políticas, institucionais e sociais em que os agentes inauguraram a sua participação partidária e o repertório de elementos articulados

* Doutoranda em Ciência Política da Universidade Federal do Rio Grande do Sul. 
naquele período e ainda acionados/disputados no discurso político atual. A importância atribuída ao "evento" e aos seus personagens já é, por sua vez, resultante de um trabalho de valorização desse momento como evento singular, seus episódios marcantes (campanhas políticas, cassações, intelectualidades, etc.) e de uma condição militante nele. Este trabalho de valorização é operado também na dinâmica de apropriação de conteúdos de identificação, de reconhecimento e de afirmação política.

Seguindo essas diretrizes de análise, a proposta é, em primeiro lugar, refletir sobre as noções de "geração", "evento" e "memória" visando localizar pistas sobre as suas apropriações. E, logo em seguida, apresentar um exercício de análise da dinâmica de construção geracional com base na verificação de materiais de consagração pertinentes.

\section{"Geração", "Evento" e "Memória": instrumentos de identificação e consagração}

Podem detectar-se duas modalidades mais gerais de emprego da noção de geração: aquela referente ao uso comum e imediato que se faz recorrentemente, com o objetivo de localizar no espaço e no tempo um grupo de pessoas ligadas por algum tipo de vínculo e destacá-las por algum aspecto, e aquela com pretensões "sociológicas" de apreensão das "gerações" a partir da definição de critérios de delimitação das suas fronteiras. O objetivo deste tópico não é nem o de inventariar exemplos de aplicação recorrente e usual da noção nem tampouco o de oferecer um catálogo bibliográfico sobre o tema. Tenta-se, isto sim, problematizar as apropriações da categoria de "geração" e pensar algumas questões práticas de pesquisa, ou seja, sobre sua potencialidade operatória.

No trabalho intitulado "Enquêtes sur les Générations et la Politique", Vicent Drouin (1995) oferece um recuo na história européia a partir do século XIX, para situar as transformações do conceito de geração e seu uso 
e, desta forma, estabelecer como as "gerações" impõem-se como atores relevantes da história. ${ }^{2}$

Já no século XX, o autor e toda a bibliografia pertinente sobre o tema ${ }^{3}$ destacam que um dos mais importantes avanços das investigações que incorporam a idéia de geração para a compreensão histórica, no que tange às ciências sociais, foi feito por Karl Mannheim, com Le problème des générations. ${ }^{4}$ Entretanto, em que pesem as contribuições fundantes da teoria mannheimiana sobre o tema geracional, há que se ter presente, conforme Drouin (1995), por um lado, que esta foi formulada com inspiração em uma situação histórica particular e, por isso, sua aplicação deve ser nuançada e, por outro lado, que Mannheim vislumbrava um sentido para a história, o que acabou refletindo na redução da geração a uma dimensão histórica em detrimento de sua dimensão sociológica, devendo esta, portanto, ser reavaliada e alargada.

Aportando em outro extremo, as proposições de Claudine AttiasDanfut (Sociologie des générations, l'empreinte du temps de 1988) enfatizam a natureza simbólica das localizações ou percepções sociais para a construção geracional. Para ela, o recorte se daria em termos de uma "duração comum" (por exemplo, a explosão de valores regionalistas em diferentes locais, sem que os sujeitos tenham qualquer tipo de convivência ou formem um grupo) e não necessariamente de experiências partilhadas. A autora, embora tenha avançado em relação à teoria de Mannheim no sentido de desvencilhar-se das fronteiras e caracterizações de uma geração constituída a partir de um evento historicamente datado (ou melhor, um período revolucionário), na ótica de Drouin, não consideraria alguns elementos presentes na teoria mannheimiana e imprescindíveis para o pes-

2 O autor dedica especial atenção às formulações de August Comte (1839 com a Psysique sociale.Cours de philosophie positive), que encontrou nas renovações geracionais as potencialidades do progresso, e na coexistência entre gerações os freios às perturbações sociais. Da mesma forma, François Mentré (1920 com Les générations sociales), que dividiu as gerações nas tipologias: familiares, espirituais, sociais e históricas, mas seguindo ainda a visão positivista de uma regularidade cíclica no surgimento das gerações sociais.

3 Ver, por exemplo, coletânea organizada por Favre e Crête Générations et Politique, Collection Politique Comparée: Econômica e PUL, 1989 e Vingtieme Siecle, Revue D’Histoire, no 22, avril-juin, 1989.

4 Este texto pode ser encontrado em Essays on the Sociology of Knowledge, N.Y., Oxford University Press, 1952. 
quisador, quais sejam os fatores políticos e eventos históricos que lançam luz ao "caso particular dos efeitos de geração acionados por períodos de transtorno político e social" (Drouin, 1995, p. 41).

A noção de evento aparece, então, freqüentemente interligada à de geração, inclusive como componente definidor da própria existência de uma "geração".

Para Jean-François Sirinelli (1996), é a partir de um evento fundador marcante que se constitui a geração. Os rumos da geração podem, assim, ser explicados pelas contingências do evento, que, por sua vez, atribui unidade e coerência a uma geração - como foi o caso de maio de 1968, evento que, inclusive, inspirou as primeiras construções mais sistemáticas sobre as "gerações" e ainda hoje é exaustivamente explorado pelos cientistas sociais. ${ }^{5}$ Seu argumento traz como premissa a idéia de que o evento é gerador de geração somente para aqueles indivíduos que não estiveram anteriormente expostos a um outro evento marcante, uma vez que esse mesmo seria gerador de geração. Ou seja, os sujeitos implicados no recorte geracional e a própria opção do recorte se dá pelo impacto de determinado evento e não de outro, o que pode ser lido como a exclusão dos sujeitos não submetidos ao evento priorizado (que reflete a incorporação de valores partilhados, etc.) da geração.

Outras proposições de Sirinelli remetem à influência das continuidades e rupturas entre diferentes gerações e ao fator idade. Segundo a "classe de idade" verificada confrontam-se eventos marcantes para as diferentes gerações, as transmissões entre elas e os rompimentos de referenciais adotados.

Uma outra perspectiva é aquela manifesta por Pierre Favre (1989), refletindo sobre a operacionalidade da idéia de "geração". Três ordens de problemas podem ser destacadas no que tange à definição/aplicação do

\footnotetext{
5 Segundo Nora: Não haveria essa efervescência de interrogações sociológicas, econômicas, demográficas e históricas em torno das gerações se não tivesse havido maio de 68. [...] Depois de tanto tempo confinada à desconfiada indiferença onde a fugidia noção vegetava, pelo menos entre os historiadores, irá suceder-se uma verdadeira proliferação de estudos de todo gênero, sequiosa pelo fantasma de 68. [...] A fabricação da sacrossanta geração de 68 não se desencadeou com os 'acontecimentos'. Ela se operou ao ritmo dos aniversários de décadas - 1978, 1988 - e em contextos históricos profundamente diferentes (1997, p. 2975).
} 
conceito de geração discutida por Favre: (1) o conceito de geração não é definível pela pesquisa de um ritmo de regularidade nem por limites prédefinidos; 2) ele é ainda menos cercável por uma análise de coortes de sondagens de opinião, em razão da não-comparabilidade das questões de uma enquête à outra (logo se torna obsoleta), e em matéria eleitoral, do encadeamento dos fatores do voto e 3) ele não é mais definível por um evento gerador tanto em razão da ambigüidade deste conceito quanto dos problemas insolúveis de fronteiras entre gerações que ele encadeia.

Segundo Favre, o primeiro grande obstáculo a ser transposto para o tratamento geracional diz respeito às tentativas de estabelecer as fronteiras que separam as gerações umas das outras segundo critérios "objetivos" previamente definidos. Sem pretender ser exaustivo, Favre apresenta cinco fatores que podem ser tomados como indicadores de diferenciação de gerações e que não necessariamente o são.

O primeiro se refere à delimitação das gerações sucessivas segundo a ordem de entrada em cena. Esta pode adquirir significados distintos conforme as contingências históricas em que os atores estréiam (alguns períodos são mais ou menos ricos em eventos consagráveis como geracionais), razão pela qual o pesquisador não pode compará-las, já que seria refém das classificações sociais e históricas produzidas pelos personagens.

A segunda diferença entre gerações, passível de ser estabelecida, diz respeito ao número de membros de uma e de outra, contudo essa "diferença geracional" pode, antes de qualquer coisa, ser reflexo de variações demográficas, ou de variações conjunturais que devem ser levadas em conta.

Pode-se ainda tomar o sistema de posições sociais em diferentes domínios como um terceiro indicador de distinção entre gerações, porém é preciso que se observe o que a configuração deste sistema de ocupação de postos deve ao fator idade (carreiras que iniciam em momentos diferentes, têm desdobramentos distintos, e os indivíduos ascendem em períodos dispares) e o que tem de geração (resultado de um conjunto de processos de consagração de eventos, feitos e personalidades que conviveram em de- 
terminada fase de uma esfera da vida social).

O quarto fator pode amparar-se na diferenciação das práticas entre as gerações sucessivas, mas é necessário que se atente para o fato de que os modos de vida, sociabilidades, gostos, etc. podem ser efeitos de inovações tecnológicas, modificações na ordem jurídica, etc. (Favre, 1989, p. 293). E finalmente o quinto aspecto passível de uso é a linguagem, que pode ser instrumento para distinguir estratos lingüísticos correspondendo às gerações a partir de um léxico que se produz numa sociedade, todavia este critério levará antes à transmissão entre gerações de um repertório lingüístico, antes que às fronteiras entre gerações (idem, p. 294).

Nota-se o ceticismo do autor quanto à utilização de qualquer critério objetivo de recorte geracional. Esses elementos acima elencados (momento de entrada em cena, número de indivíduos participantes, as posições sociais alcançadas, as práticas e a linguagem) precisam, segundo Favre (1989), estar articulados à dinâmica analisada. Assim, esses componentes se relacionam ao espaço no qual atuam os indivíduos (condições históricas), bem como aos significados que os sujeitos incutem a tais critérios, aparentemente dotados de objetividade.

Este aspecto vai ao encontro da abordagem de Nora (1997), que parte da inviabilidade de definição a priori de critérios objetivos (por exemplo, demográficos ou etários) na demarcação de uma geração, porém esses aspectos, levando em consideração o universo de análise, não deixam de interferir na sua delimitação e para que ela se torne um modo de identificação por excelência da contemporaneidade dos agentes implicados.

As "gerações", para Favre, não são grupos homogêneos de pessoas com as mesmas concepções, crenças, desejos, frustrações, não se delimitam por classes de idades, estilos de vida, nem mesmo por um "patrimônio" comum político, intelectual, moral, etc. A análise de "grupos" revela heterogeneidades e divergências no seu interior e nos itinerários dos seus membros. Devem observar-se, isto sim, as lógicas específicas que incidem na construção de referências comuns na diversidade, ou seja, quais os 
elementos intervenientes, as modalidades, as datas marcantes, etc. que produzem estes pertencimentos. ${ }^{6}$ Tal forma de tratamento consiste na apreensão controlada e sistemática dos critérios intrínsecos.

É preciso também, conforme Favre (1989), atentar para critérios extrínsecos de formação da idéia geracional. Com efeito, a noção de evento se constitui em um critério extrínseco que viabiliza a constituição de precisões formais ao objeto de análise, e sua centralidade consiste no fato de que, nele, uma geração constrói sua identidade, experimenta sua contemporaneidade, se apropria de seu tempo, funda sua memória coletiva (Favre, 1989, p. 309). Isto não significa dizer que o evento "fabrica" uma geração, como se o evento gerador fosse exterior aos homens que dele participam, ao contrário, são os homens que fundam o evento e que the conferem seu valor de evento (idem, p. 312). Com esse argumento, Favre se distancia do enfoque proposto por Sirinelli anteriormente apresentado, segundo o qual o evento é definidor da geração.

A relevância da noção de evento para residiria na associação que ele é capaz de fundar entre a exposição inaugural a que se submete um conjunto de indivíduos e os feitos históricos cuja autoria é reivindicada:

Essa referência à primeira 'exposição' a um evento se funda sobre a idéia de que cada geração se forma quando seus membros são jovens, mas não porque a juventude é um período onde tudo é possível, onde a disponibilidade é grande (o que somente é uma imagem social), ${ }^{7}$ mas porque ela não conheceu ainda nenhum

6 É nesta idéia de identificação ou reconhecimento de contemporaneidade distintiva que reside a chave dos vínculos geracionais, isto é, os sujeitos se identificam e identificam os outros como pertencentes à mesma geração e operam a mesma atribuição tanto para os mais próximos como para seus concorrentes (Girardet, 1983, p. 184).

7 A não-essencialidade no uso da categoria "juventude" significa considerar que: Somos sempre o jovem ou o velho de alguém. É por isto que os recortes, seja em classes de idade ou em gerações, variam inteiramente e são objetos de manipulação... Cada campo possui suas leis específicas de envelhecimento: para saber como se recortam as gerações é preciso conhecer as leis específicas do funcionamento do campo, os objetos de luta e as divisões operadas por esta luta. Isto é muito banal, mas mostra que a idade é um dado biológico socialmente manipulado e manipulável; e que de fato de falar dos jovens como se fossem uma unidade social, um grupo constituído, dotado de interesses comuns, e relacionar estes interesses a uma idade definida biologicamente já constitui uma manipulação evidente (Bourdieu, 1983, p. 113, grifos no original). Assim ao verificar a manipulação da categoria "juventude", suas interdependências com o espaço político e sua transformação em identidade, que aproxima uma série de sujeitos (dotados de atributos e crenças bem específicas) e excluem muitos outros (não só os mais velhos, mas também outros jovens não militantes e não esquerdistas), tem-se um exercício de demonstração da construção de uma categoria e seus efeitos na luta política. 
evento gerador (Favre, 1989, p.311).

O autor acrescenta as seguintes interrogações para os desdobramentos de um estudo deste tipo:

Por quais mecanismos sociais um evento é reconhecido por uma geração como constituindo 'seu tempo inaugural'? Como a memória coletiva assegura a conservação e a transmissão - a transmutação - de uma certa imagem do evento? Quais são as variações do poder integrador da memória coletiva, da riqueza da representação do passado (idem, p. 313).

A passagem acima conduz à explicitação dos efeitos do trabalho de memória sobre a idéia de geração. A interferência da memória pode então operar como justificativa do recorte geracional, quer dizer, tal como propôs Halbwachs (1968), como indicação do modo de referência ao passado, que exige assumir um grupo social como base, recortado e provido de relativa coesão e estabilidade, todavia, este último não deve forçosamente ser homogêneo. Ele deve, entretanto se definir por uma experiência partiIhada, um relato comum sobre o passado (Halbwachs, 1968, p. 76). Em que pese a Halbwachs, segundo as observações de Lins de Barros (1989), reivindicar uma concepção de memória indissociável do caráter social que Ihe dá existência, a intervenção dos homens se dá quando cada um deles:

[...] traz em si uma forma particular de inserção nos diversos meios em que atua. Para ele [Halbwachs] cada memória individual é um ponto de vista da memória coletiva, e esse ponto de vista varia de acordo com o lugar social que é ocupado; este lugar, por sua vez, muda em função das relações que se tem com outros 
meios (Lins de Barros, 1989, p. 31).

Nora (1997), por seu turno, problematiza a configuração de uma memória de grupo nos termos sugeridos por Halbwachs, em favor da existência, sim, de lugares de memória, isto é:

Os lugares onde ela [a memória] se condensa e se exprime têm em comum o fato de serem lugares comuns, centros de participação coletiva, mas passíveis de uma imediata apropriação pessoal... a memória geracional advém de uma sociabilidade de conjunto histórico e coletivo para se interiorizar até as profundezas viscerais e inconscientes que comandam as escolhas vitais e as fidelidades reflexas. O 'eu' é ao mesmo tempo um 'nós' (Nora, 1997, p. 3003).

Deste modo, pode-se, em última instância, conceber a noção de geração como indissociável desta de memória, ambas historicamente construídas. Quer dizer, é pertinente falar de memória geracional para as situações de maior "tomada de consciência" de pertencimento de geração (Nora, 1997).

A lembrança, pois, é guiada por uma rede de significações e relações sobre e constituídas no "presente" informado pelo "passado", e o "passado" sendo dinamicamente reconstituído com base no "presente". A alusão ao passado permite reconstituir justificadamente a trajetória que se seguiu e, assim, revelar uma dinâmica de constituição e fortalecimento de grupos de pertencimentos e de fronteiras sociais, de expectativas e desencantos, de complementaridades e oposições irreversíveis (Pollak, 1989).

\section{Memória Geracional: depoimentos de (auto) consagração}

As análises a seguir permitem apreender que a utilização espontânea da idéia de "geração" parece responder ao trabalho incessante (e nem 
sempre racionalizado como tal) por parte dos personagens de ordenar pertencimentos relacionais, ou seja, em oposição a "um outro". A constituição geracional parece, igualmente, promover uma visibilidade social e a possibilidade de contar com solidariedades (Favre, 1989, p. 318). Soma-se a estas que:

A divisão em geração exprime igualmente uma relação coletiva no tempo, é uma máquina a fabricar um tempo histórico portador de sentido social. Sabemos há muito tempo o quanto são fundamentais os mecanismos que estruturam as categorias sociais do conhecimento coletivo. Um povo vê sua história introduzindo sem parar pontos de entender acontecimentos, e esses acontecimentos-entendimento, e esses são percebidos indissociavelmente dos atores que os tem dominado (sic) (Nora, 1997, p. 2976 e 3005).

Afirma-se que as narrativas sobre o passado e suas lembranças, fazem emergir uma idéia de geração cuja consagração se dá na ativação de um pertencimento (individual ou de grupo) e na celebração de um evento ("a luta contra a ditadura militar") instituído na sua singularidade histórica.

... de parte em parte, atravessada de história, pelo simples fato de que se trata antes de tudo de um fenômeno largamente construído, retrospectivo e fabricado. A geração não tem nada de uma faísca no ardor da ação: é uma constatação, um balanço, um retorno sobre si para uma primeira inscrição na história... A geração é produto da lembrança, um efeito de rememoração. Ela somente se concebe por diferença e por oposição. (Nora, 1997, p. 2999). 
Para tanto, são utilizados os seguintes tipos de materiais: algumas passagens dos depoimentos em que os sujeitos revelam uma identificação geracional e um "Grande Expediente" em homenagem póstuma a André Cecil Forster. ${ }^{8}$

O grande marco é que todas as pessoas que estiveram envolvidas nesse período estão em algum segmento participando. Em segundo lugar, reconhecem todos entre si, mesmo que haja distância política e ideológica, há respeito e admiração pelo trabalho fecundo que foi realizado na ocasião. Que é difícil construir às vezes, mas eu acho que, em política, a primeira coisa que tem que construir é esse respeito, essa admiração recíproca. Porque cada um defendendo suas idéias é melhor que ter uma visão de que é adversário perene. Ninguém é adversário perene. Existem motivos que são às vezes superiores às divergências e no qual as pessoas podem se encontrar. Uma outra marca é que ninguém teve medo de enfrentar a realidade. Claro que alguns dos nossos passaram por privações, dificuldades, penalizações de todo tipo e de toda sorte, mas existiram outros que também procuraram fazer uma composição de um modelo onde todos pudessem sobreviver sob o ponto de vista político pelo menos, da

8 André Cecil Forster realizou seus estudos primários e secundários em Santa Cruz do Sul, lugar onde nasceu. Em 1964, transferiu-se para Porto Alegre quando ingressou na Faculdade de Ciências Sociais da Universidade Federal do Rio Grande do Sul. No mesmo ano, trabalhou no Instituto Brasileiro de Reforma Agrária como assessor técnico. Durante o período universitário foi secretário-geral do Centro Acadêmico da Faculdade de Filosofia da UFRGS, entre 1965 e 1966, e, depois, seu presidente, entre 1966 e 1967. No início dos anos 70, assumiu a presidência da Associação Gaúcha dos Sociólogos, exercendo o cargo até o ano de 1977. Também no ano de 1972, ele ingressava na Universidade do Vale do Rio dos Sinos para lecionar Sociologia e Ciência Política. Como professor universitário permaneceu até o ano de 1982. Ingressou no MDB, na assessoria do então deputado estadual Pedro Simon, na época presidente do partido, no início da década de 70 . .No ano de 1972, criava-se o IEPES - Instituto de Estudos Políticos, Econômicos e Sociais - e, em 1978, foi candidato a deputado estadual representando o Instituto. Foi eleito vereador, em 1982, exercendo seu mandato até o ano de 1986 . Nesse período (de 1982 a 1984), foi líder da bancada; de 1984 a 1986, exerceu o cargo de presidente da Câmara de Vereadores. Em 22 de março de 1996 recebeu, na Câmara de Vereadores, o título de Cidadão Honorário de Porto Alegre. Foi ainda candidato a deputado estadual constituinte em 1986, Secretário de Estado e presidente estadual do PMDB na década de 90. 
sua prática. Eu acho que o que está em exercício aí e o que tem outro valor é uma prática, um tipo de, aprender a fazer reunião, a levar as pessoas a se organizarem, a participar cada vez mais, a evoluir no pensamento, a evoluir na forma de administrar e quantos e tantos quantos não estão aí administrando, não digo uma prefeitura, um governo estadual, mesmo nacional né!... o [ex] presidente da república [Fernando Henrique Cardoso] era dessa época, era do Centro Brasileiro de Análise e Planejamento que seguidamente estava no RS dando palestras no lepes junto com o Chico de Oliveira... o Weffort, bom tantos e tantos, Eduardo Suplicy, Paul Singer, Roberto freire, por aí vai... A grande marca é que existiam forças democráticas engajadas politicamente, mas que tinham a capacidade de fazer aglutinação de todas as forças. E me parece que hoje isso é bastante necessário ainda (sic) (deputado estadual do PMDB, 53 anos).

... uma geração inteira deve a sua formação política aos debates daquela mesa democrática do lepes... A formação política eu devo ao lepes... presenciar um debate sobre a conjuntura que era honestíssimo do ponto de vista intelectuel, que era possível se dar organizadamente sem uma liderança visível e que posições antagônicas estavam constantemente postas no debate. Dizer 'ó, não concordo com a tua posição, acho ela conciliadora, e tal, tá propondo a conciliação de classe', 'não, seu trotskista, o escambal..'. Visto de hoje, eu posso dizer que faria tudo de novo. Tive o privilégio de trabalhar com pessoas com as quais até hoje eu tenho laços de amizade, que eu respeito profundamente. Se tu pegar os quadros que estão mudando o Rio Grande do Sul, todos eles participaram conosco daquele período, mai- 
or ou menor. O Raul Pont, Tarso Genro, o Adelmo que morreu, o Olívio que foi preso pela polícia federal no dia exato que o Brizola pisava no RS... nós exigimos que pra falar com o Brizola a segurança fosse dispensada, o Brizola mandou a polícia pro raio que a parta e aí nós entramos pra falar como ele, era o Glênio Perez, eu, Carlos Araújo, a Dilma, o Miranda economista, o Paulão [Paulo D'Ávila]... O André [Forster], apesar das divergências políticas que nós sempre tivemos, os demais da posição dele... Pedro Bisch Neto, o Cristiano Tatsch... (assessor de imprensa da Secretaria de Minas e Energia, 48 anos, PT).

As passagens acima permitem apreender a importância atribuída a um aprendizado comum que se concentra principalmente no caráter de formação política e intelectual adquirido na participação de um evento marcante maior (luta contra ditadura). Tal possibilidade de "aprender" está relacionada à existência de espaços de elaboração e assimilação intelectual em que o Instituto de Estudos Políticos, Econômico e Social (IEPES) é referido como a expressão privilegiada.

Ao mesmo tempo, fica evidente a instrumentalização dos conteúdos caracterizados como "intelectuais" na disputa política naquele período e a apresentação disso quase como a "gênese" de determinadas características e valores presentes nas disputas políticas posteriores. Assim, as habilidades como "fazer reuniões", "organização", "participação", "aglutinação", "debater", etc., cuja origem é conferida às experiências de um momento, são interpretadas e identificadas como atributos que persistem.

Além disso, há referências aos vínculos estabelecidos e à experiência compartilhada naquele momento como componente significativo nos itinerários dos quadros políticos. A reivindicação de um "reconhecimento entre si", o contato com intelectuais e políticos, os "laços de amizade" e a 
utilização de expressões como "admiração" e "respeito" revelam um sentimento de contemporaneidade que se constitui também por sua dimensão afetiva, ou seja, a construção geracional é fruto de estruturas de sociabilidade que informam origens de solidariedades que são acionadas em narrativas sobre o passado e balizam as lutas no presente.

Este círculo de reconhecimentos é sedimentado pela participação comum em episódios significativos e criadores de vínculos. Entre estes, as eleições, sobretudo aquelas ocorridas em 1976, são constantemente sublinhadas. Como é possível notar nos fragmentos abaixo:

Em 76, aquela geração do MDB jovem saiu da adolescência. Porque desse período aí um processo de relações políticas vai se consolidando... Em certa medida a densidade da ação política nessa época resulta nisso, isso significou dentro do $M D B$, nem sei se prosseguiu atuando no $M D B$ jovem, com o mandato já se é do MDB adulto. A própria distinção do MDB jovem já era uma maneira de se criar um dique de contenção da esquerda... A campanha do Marcos [Klassmann] e o André [Forster] foram as campanhas mais fortes assim, do ponto de vista de postulação, de posicionamento, foram as campanhas mais fortes, eu acho que um sucesso se credita a isso também. A relação era tão ruim de composição dos candidatos que mesmo as idiossincrasias e as diferenças, a diferença do Coppeti para os demais candidatos do MDB era uma coisa gritante. Então eu diria que a relação embora fosse de disputa no contexto global, acaba sendo de cooperação porque era a mais próxima (jornalista e empresário, 46 anos, PT).

A partir das eleições de 76 se divide praticamente a esquerda daquela nossa geração... A pulverização da 
esquerda começou a partir de 76, 77 a formular hoje a continuidade desses projetos. Então naquele momento a disputa da esquerda já ocorria internamente tendo em vista que cada um desses grupos, dessas lideranças passavam a integrar um grupo da esquerda, um setor da esquerda... Chegou a eleição de 76 e foi o ano que nós passamos da vida universitária pra participar do processo eleitoral (vereador, 50 anos, PSDB).

Pode-se ressaltar, pois, nos relatos a ativação da categoria de "geração" associada à construção de espaços no interior do MDB, da política e da esquerda. Deste modo, os personagens se inserem enquanto grupo geracional no deslocamento de uma condição de atuação política restrita ao espaço disponível para a "juventude" - associada à idéia de "esquerda" - para uma condição de concorrentes na luta política do Rio Grande do Sul.

A centralidade da campanha de 1976 como o momento de passagem, ou melhor, o caráter de divisor de águas assumido a constitui como um dos eventos marcantes no itinerário político dos entrevistados e, neste sentido, duas considerações são relevantes. Em primeiro lugar, no que tange à apreensão dos momentos eleitorais no período estudado, este é expressão das bandeiras forjadas na "juventude" e, ao mesmo tempo, é a afirmação daqueles indivíduos como lideranças políticas. Em segundo lugar, no que diz respeito à plasticidade da categoria de "juventude", uma vez que esta não se define por critérios objetivos de classificação (etária, por exemplo), mas por uma mudança de condição e reconhecimento na luta política. A "juventude" como categoria homogeneizadora das ações extrapartidárias ou extra-eletivas, quando transposta para o jogo político eleitoral produz sua "pulverização" ou a entrada numa "fase adulta". Quer dizer, a passagem da "juventude" à "vida adulta" é medida muito antes pela temporalidade da política e pelos itinerários da "geração" do que por mudanças da condição etária. 
Da associação entre "juventude" e "geração", agilizada pelos sujeitos, é possível extrair, então, que, de uma etapa transitória da vida, a condição de "jovem" torna-se um princípio ordenador de uma imagem distribuidora dos papéis e dos lugares, um fim em si mesmo definindo os pertencimentos, e quando os jovens assumem o papel dos adultos, tomam a si a dinâmica da transformação política e social (Nora, 1997, p. 2986-1987).

Por sua vez, o trabalho de memória sobre a categoria geração também sofre os efeitos das transformações no estatuto dos agentes que elaboram as releituras sobre uma condição etária. Com efeito, o "envelhecimento", indistintamente social, político e biológico dos indivíduos, acaba originando referências estandardizadas, como as presentes nos relatos que seguem:

Todos nós, a geração de 70, tínhamos uma preocupação política, uma preocupação social e política e que em um momento de ditadura, ela se expressou de alguma forma. Então, nós tínhamos uma, quando a gente entrou na política, nós tínhamos pela frente o paredão da ditadura, o paredão da contra-cultura, dificuldade de se reunir da dificuldade de continuar aprendendo e, claro que o que unia o pessoal todo era a luta contra a ditadura... Nós, da década de 70, nós estávamos vivendo uma revolução de costumes... então tinha música, tinha Gilberto Gil, mas eram muitas coisas ao mesmo tempo. Tinha o marxismo, a atividade política que era um pouco perigosa, era sexo, descoberta da relação afetiva... a descoberta da percepção, da análise, drogas... tudo isso. Nós tínhamos uma coisa muito rica na década de 70 (empresário e economista, 48 anos, PMDB). 
Esse período foi assim, riquíssimo, bárbaro. Eu costumo dizer que a gente é o rescaldo, quase o final dessa geração, dessa luta contra a ditadura, então nós nos construímos assim como militantes de uma maneira muito importante eu acho. Eu sempre digo assim que eu tenho claro ainda mesmo que mudado tantas coisas na sociedade, e tal, eu tenho muito claro qual é meu horizonte, qual é meu ponto de vista frente as coisas, né, mesmo que eu tenha mudado a minha situação econômica, porque eu era uma estudante, não tinha grana nenhuma, às vezes não tinha dinheiro não só pra comprar cerveja pros meus amigos na minha casa, como não tinha dinheiro pra comprar cachaça e limão tinha no pé. Quer dizer, imagina, era aquela coisa bárbara assim, não tinha jeito de nada, arroz com lingüiça era uma lingüiça e dois quilos de arroz, tava bom pro sábado de noite, né. Então assim, o fato de a gente, até do ponto de vista profissional, acho que muitos de nós deu certo amplamente, não só do ponto de vista técniCo, mas do ponto de vista econômico, muitos de nós se mantém com uma postura muito boa, frente a vida, frente ao mundo... Um exemplo importante disso é o Tarso, é uma pessoa com um sucesso estatal digamos, quero dizer um sucesso social é uma pessoa que consegue se manter muito firme com suas coisas, com seus projetos (médica e vice-presidente do Sindicato dos Médicos do RS, 48 anos, s/ filiação).

Nos depoimentos acima, a categoria de geração aparece relacionada principalmente à vivência em um processo mais amplo "a luta contra a ditadura" e sua definição encerra uma idéia de temporalidade, ou seja, revela uma continuidade entre gerações que lutaram contra a ditadura. As ênfases recaem sobre o caráter lúdico atribuído à militância política e esta ludicidade se investe de uma carga de desprendimento e responsabilidade 
(política e social) que é saudada por seu resultado, isto é, pelos êxitos em termos materiais conquistados e em termos de posturas diante do mundo daqueles que conviveram sob as mesmas condições.

Os entrevistados então não estão apenas situando um ambiente ou uma série de manifestações sob um mesmo evento (luta contra a ditadura), mas autoproclamam toda a "geração" por um sentido missionário, poético, social e político, valendo-se legitimamente da autoridade juvenil investida pelo "mundo adulto" no qual se localizam nos dias atuais (Nora, 1997). Assim, conforme Nora:

O que dá ao grupo... sua missão poética, social e política, é sua condição histórica: ela é a geração diferenciada. É isso o que faz ser imediatamente reconhecida e saudada por aqueles mesmos que ela pretende substituir... O sentimento de perseguição é o ingrediente capital à constituição de uma consciência de geração (Nora, 1997, p. 2989-2991).

Desta forma, a celebração de um período como um "momento extraordinário" se dá simultaneamente à atribuição de extraordinariedade da intervenção dos agentes neste evento. Por conseguinte, da participação e identificação neste momento, os homens políticos extraem trunfos (de experiência militante, de dedicação a uma causa, de intervenção no desencadeamento de um processo político, etc.) acionados e disputados nos desdobramentos políticos posteriores. A possibilidade de utilizar, na luta política (explicitamente ou não), tais trunfos, disputar objetos forjados naquele momento e dar-lhes relevância paradoxalmente implica a existência de um reconhecimento mútuo entre os protagonistas envolvidos, e este reconhecimento, por seu turno, é sintetizado no uso da categoria de "geração".

Ou seja, a referência geracional não explicita as diferenças que a compõem, mas proclama uma horizontalidade entre seus membros, portanto, banaliza uma experiência compartilhada para se tornar um lugar de 
memória e:

... se ela é lugar de memória, é pelo jogo simples e sutil da memória e da história, a dialética eternamente prenhe de um passado que habita o presente, de atores tornados suas próprias testemunhas, e de novas testemunhas transformadas por seu turno em atores (Nora, 1997, p. 3007).

\section{Homenagem Póstuma a André Forster: o "grande- expediente" como um lugar de memória}

O propósito desta seção é realizar uma análise a partir de um material empírico específico e localizar alguns dos elementos discutidos até então, a partir do Grande-Expediente da Assembléia Legislativa do Rio Grande do Sul, realizado no dia 11 de dezembro de 1997, em homenagem ao primeiro ano da morte de André Forster, presidente regional do PMDB (Partido do Movimento Democrático Brasileiro). Aqui os nomes dos atores são mantidos uma vez que se trata de um material produzido e direcionado ao "público".

Antes de tudo, deve-se ressaltar que o que está em questão é como os depoimentos de celebração de lideranças, após seu falecimento, possibilitam apreender uma gama de sentidos compartilhados e disputados, e como estes se constituem na consagração não só do «morto», mas de categorias como "geração" e "eventos" (momentos ou períodos) significantes, bem como dos próprios agentes que se autorizam a depor sobre o homenageado.

Sendo assim, podem adotar-se algumas indicações de Yves Hélias (1979), no sentido de considerar a consagração dos mortos como reflexo de uma "estrutura de trocas simbólicas" impulsionada pela crença na fun- 
ção gratificante desempenhada pelo indivíduo (em vida). O “julgamento valorizante" das qualificações ou ações do indivíduo legitima a realização de "homenagens" que acaba assumindo o caráter de retribuição suscitada pelo reconhecimento por parte daqueles que permanecem vivos. Este sentimento de "dívida simbólica" com o indivíduo privado de vida, não se funda apenas na consagração de sua "obra" (num sentido bem amplo), mas simultaneamente a consagração de um universo de significados - no caso de um período repleto de lutas, eventos, feitos, marcas - que, em última instância, consagra aqueles que oferecem a homenagem. Estes, além de "saldar" uma dívida histórica com o homenageado, retiram do ritual, através dos vínculos atualizados nas falas, trunfos políticos para si mesmos.

Deste modo, os elementos articulados à figura do homenageado permitem a compreensão de todo um jogo de papéis no qual o funcionamento é particularmente esclarecedor, além das lógicas que tornam o homenageado "credor" e aqueles que homenageiam, "devedores" (Hélias, 1979, p. 747).

A importância de Forster enquanto referência de uma geração evidencia-se facilmente nos depoimentos quando de seu falecimento a 9 de dezembro de 1996. A caracterização do seu "legado" é a forma como recorrentemente se reivindica a conservação de sua "memória", sendo revelador de uma série de princípios compartilhados. Isto pode ser observado na descrição dessa trajetória exemplar, que é fornecida por um dos principais atores e propagadores desta memória, no dia seguinte à morte de Forster:

Poderíamos falar do líder estudantil, do sociólogo, do vereador, líder da bancada e da Câmara Municipal, do diretor da Metroplan ou do Secretário de Ciência e Tecnologia, etapas da sua vida onde esteve sempre presente a marca do seu talento e competência. Mas lembremos o presidente do IEPES (Instituto de Estudos Políticos, Econômicos e Sociais) e o dirigente estadual 
do PMDB. Forster esteve à frente dos que optaram pela resistência democrática ante o regime ditatorial. Coordenou um organismo do MDB que representou, à certa altura, a única trincheira e voz dos que não concordavam com os desmandos do autoritarismo. Organizou corajosos painéis, trazendo figuras de peso na luta pela democracia, como Ulysses Guimarães, e intelectuais identificados com o projeto das forças democráticas, como o então professor Fernando Henrique Cardoso (Por José Ivo Sartori, Seção Opinião do Diário da Assembléia, 10/12/96, p. 2).

Deste modo, a utilização do Grande-Expediente para homenagear "a memória de André", proposta pela bancada do PMDB, constitui-se em registro de consagração de um homem, mas também de uma época, estes viabilizados pela estratégia de consagração de um partido que herdou a sigla da oposição (MDB) e reivindica a herança de sua história e de sua posição no campo político. A descrição pura e simples deste material já explicitaria sua compatibilidade com os argumentos expostos na seção anterior, dada a riqueza para a identificação da gama de classificações que emergem do que se pode chamar de uma "memória de geração", bem como da transmissão dessa memória.

Por tudo isso, as homenagens proferidas ao "homem político", falam muito não apenas dos atributos acumulados que destinaram a ele uma posição de destaque, mas sobre a existência de uma referência comum aos diferentes lideres políticos, das diferentes siglas partidárias, que se manifestaram para depor sobre o homenageado. Os pronunciamentos destes agentes neste espaço de consagração, falam, então, muito sobre eles mesmos, das suas próprias experiências e referências, da seleção operada quando da leitura sobre eventos marcantes e, para aqueles que não o vivenciaram, da aquisição destes conhecimentos. Pedir um "aparte", for- 
malidade desta situação institucional, significa, desta forma, confirmar um posicionamento, reconhecer-se com autoridade para posicionar-se, é partilhar de uma doxa, é reconhecer no homenageado uma pessoa à altura para homenagear-se e inclusive sentir-se incumbido de saldar uma dívida com o homenageado e com a sua obra.

\section{A homenagem}

O discurso de Giovani Feltes (deputado estadual do PMDB, organizador da atividade) articulou a valorização de traços do caráter de André Forster com suas ações e convicções políticas. A reunião dos adjetivos qualificadores da personalidade do político (competência, profissionalismo, dignidade, ativismo, etc.), posteriormente reafirmados nos "apartes", comporiam o "legado" deixado, ou seja, "um grande patrimônio ético e político". Adiciona-se a isso, a ênfase de que os primórdios deste capital residiriam no período ditatorial, marcando a singularidade das ações, não de um "jovem", mas de uma "juventude" que localiza nele, agora com um olhar retrospectivo sobre a História, um parâmetro de conduta, mas igualmente de distinção e singularidade (tal referência, ou reverência, repete-se em outros discursos, até nos mais imprevisíveis, como será ilustrado mais adiante): "André Forster é resultado político e ético de uma parcela da nossa juventude que ingressou na universidade em 1964, defrontando-se direta e imediatamente com o regime militar que então se instaurava" (Giovanni Feltes, PMDB).

Porém é na reprodução do relato de Sérgius Gonzaga, concernente à ocasião da eleição de Forster à presidência do diretório acadêmico da Filosofia, que sobressai o peso dos significados atribuídos àquele momento, que imprimem os princípios de constituição de uma geração, sublinhando o sentido de "missão" que lhe confere, colado ao vínculo etário, sua 
homogeneidade, seu efeito sobre-regenerador: ${ }^{9}$

Estamos no Bar Alaska. André Forster acaba de ser eleito presidente do Centro Acadêmico da Filosofia da UFRGS. Comemoramos a sua vitória. Na mesa, representantes de todas as facções da esquerda do movimento estudantil. Apesar dos desvios ideológicos de algumas tendências, nos julgamos a vanguarda indiscutível da luta popular contra a ditadura. Somos jovens, apenas e tão-somente jovens, e alimentamos grandes esperanças.

A heterogeneidade de tendências políticas e ideológicas patentes naquela ocasião se manifesta, como já foi dito, na heterogeneidade dos dirigentes políticos firmando declarações na sessão solene da Assembléia Legislativa: representantes de diferentes partidos ${ }^{10}$ prestaram seu testemunho, num total de 16 pronunciamentos. Para fins de ilustração foram selecionados fragmentos dos seis relatos considerados mais representativos em termos de filiação partidária, e mais exemplares na explicitação de princípios compartilhados.

Não só como representante de minha bancada mas muito decididamente por meu sentimento pessoal, não poderia deixar de falar hoje...para a geração que compartilhou das etapas das lutas de André Forster, a esta oportunidade de homenageá-lo. E são várias as gerações. Sou talvez da primeira. Fui presidente do Centro Acadêmico Franklin Delano Roosevelt da Faculdade de Filosofia em 1963, destituído pelo golpe militar de 64. Se a minha memória não me está traindo, André Forster e eu, quando recuperamos o Centro, vencemos, com a candidatura de Clóvis Paim Grivot, que foi o primeiro

9 A idéia de efeito sobre-regenerador foi concebida por Daniel Gaxie (1977) para definir a habilidade de determinadas estruturas militantes em criar outras formas de gratificações (não materiais), baseadas na afirmação de valores como integração social, sentimento de participar de uma "causa justa" e engajamento em uma "aventura rica de sentido" e de "devotamento". 10 Valdir Fraga (PTB), Jussara Cony (PC do B), Vilson Covatti (PPB), Beto Albuquerque (PSB), Onyx Lorenzoni (PFL), Vieira da Cunha (PDT), João Fischer (PPB), Divo do Canto (PTB), Flávio Koutzii (PT), Francisco Appio (PPB), Alcides Vicini (PPB), Eliseu Santos (PTB), José Ivo Sartori (PMDB), Paulo Odone (PMDB), Giovane Feltes (PMDB) e Quintiliano Vieira (PMDB). 
presidente depois da intervenção - André Forster foi o seu sucessor... As cenas do Bar Alaska, onde eu estava, lembram todo um episódio, toda uma geração... Quan do se pode falar de uma pessoa, que, em várias etapas da sua vida, foi capaz de lutar, foi capaz de discernir e, muitas vezes, escolheu o lado mais difícil e, quando aqui se diz que foi um lutador pela redemocratização do País, teve um papel fundamental na organização e na articulação da intelectualidade neste Estado, teve um papel fundamental na articulação do próprio $M D B$, naquela oportunidade, o centro de aglutinação e de ação política da proposta que tentava trazer o partido à normalidade institucional e democrática - isso significa discernimento, visão e, principalmente, persistência (Flávio Koutzii/PT).

Não desejava me manifestar. Até pensei, como Chico Buarque de Holanda, 'falando sério, preferia não falar'. Quando o deputado Flávio Koutzii, muito emocionado, não conseguia prosseguir o seu aparte, pedi a ele que continuasse, pois me sentia exatamente na mesma condição, pela amizade, pela identidade política ou por outras razões.... André Forster era tão habilidoso com a mente que - muitos deputados devem ter lembrança disso, especialmente o Sr. Rospide Netto -, foi no Rio Grande do Sul, nas promoções do IEPES, que vieram a ser conhecidos Fernando Henrique Cardoso, Francisco Wefort, Chico Lopes e, posteriormente, Fernando Gabeira. Enfim, todos os grandes cientistas políticos brasileiros oriundos do Cebrap, que eram desconhecidos no País, vieram para cá nessa época, além do Arcebispo Dom Paulo Evaristo Arns e outros... André Forster nos dá a capacidade de entender que temos que continuar lutando, cada um no seu partido, cada um no seu lugar, para realmente valorizar a atividade política feita com dignidade... (José Ivo Sartori/PMDB). 
Os dois fragmentos acima referidos permitem recuperar algumas discussões precedentes: num primeiro momento, no tocante à idéia de geração e às noções nela imbricadas (memória, espaços de socialização, identidade e evento) e, num segundo momento, no que tange à interferência intelectual nos espaços de elaboração política e vice-versa.

Inicialmente destaca-se a cumplicidade estabelecida entre dois protagonistas, contemporâneos de Forster no momento histórico celebrado como de "luta pela redemocratização". Embora atualmente pertencentes a partidos políticos oponentes (PT e PMDB), a situação que se apresenta (o peso de significações que ela expressa) promove a neutralização (mesmo que parcial) de diferenças formais e revela um nível de solidariedade. Deste modo, evidencia-se um vínculo localizado no passado, mas sempre prestes a interceder no presente, e quando isso acontece, tem-se uma percepção de geração: "sentir-se na mesma condição".

A referência comum constituída pelos atores é viabilizada por um enquadramento de memória (Pollak, 1989) que retira do momento histórico e da experiência vivida em tal momento, elementos que ordenam posições e sentidos retrospectivamente. Termos como "sentimento pessoal", "laços de amizade", "identidade", convivência em espaços lúdicos (bar Alaska), unem indivíduos sob a noção de geração (ela mesma reivindicada nas falas). Adiciona-se a isso que referidos valores adquirem um sentido político quando articulados a uma idéia de "missão histórica" que sintetiza a mobilização dos atores pela "luta democrática".

Os argumentos expostos acima apontam para a constituição de uma identidade. A participação militante produz, então, a valorização dessa identidade quando privilegia a concepção do engajamento político como algo transcendente à biografia pessoal (Neveu, 1996). No caso analisado, observa-se o esforço nesta direção, isto é, a missão proclamada pelo pertencimento de geração, e seus objetivos práticos (a "democratização") se sobrepõem às individualidades.

Fica patente igualmente a importância conferida à interface com os 
intelectuais. Esta se expressa nas referências à organização da intelectualidade, à presença de intelectuais com notoriedade acadêmica nacional no Rio Grande do Sul e, principalmente, ao papel de André Forster na estruturação do IEPES.

O período de maior intensidade de atividades promovidas pelo IEPES converge com a demarcação dos empreendimentos mais sistemáticos dos intelectuais no campo político. Ou seja, no início da década de 70, os intelectuais se apresentavam como ator coletivo relevante, encabeçado por lideranças formadas no seu meio, comungando de crenças e fixando estratégias de intervenção. A veemência do processo de abertura política manifestava-se já, contando com a integração efetiva dessas lideranças acadêmicas no debate político propriamente dito, através do qual a oposição se fortalecia. Este mergulho na política se cristalizou, inclusive, na revisão do programa do MDB em 74 (Pécaut, 1990, p. 260).

Assim sendo, o ano de 1974 foi marcado pelo engajamento decisivo dos intelectuais na "causa democrática". O destaque de Fernando Henrique Cardoso (citado no relato) é o mais notável no que tange à gama de investimentos dedicados às formulações teóricas e posturas práticas a serem adotadas pela oposição naquele momento. ${ }^{11} \mathrm{O}$ acúmulo de recursos no campo intelectual lhe garantiu legitimidade e êxito no campo político. ${ }^{12}$

As formulações coladas na conjuntura definem fortemente o pensamento democrático ${ }^{13}$ elaborado pelas Ciências Sociais no Brasil. Após 73, os textos destinados ao tema da democracia (na sua maior parte) se consti-

11 Para Virgínia Fontes (1996), os dois textos que podem ser considerados fundadores, pois que reintroduzem o tema da democracia no interior do universo intelectual, são os de Fernando Henrique Cardoso: "A questão democrática" de 1973, e Wanderley Guilherme dos Santos, com a tese da "descompressão gradual" para chegar à democracia, também de 1973. A autora aponta como interlocutores de Cardoso a "elite dirigente (presidente, militares e ideólogos), os "intelectuais", não mais de formulação de um projeto de salvação nacional e a "oposição», sugestionando o investimento no espaço político sem mais "sonhar com um via 'condottiere'" "ou de apagamento de conflitos (p. 55).

12 Sobre isso, ver Pécaut (1990) e Fontes (1996), Miyamoto (In: Lamounier, 1980).

13 Segundo Pécaut, este "pensamento democrático" fundamenta-se na reativação da sociedade civil: este é na verdade o lema que se difundirá no quadro de abertura. Ele não comporta quaisquer concessões ao liberalismo ou exaltações à democracia formal (1990, p.290). A ordem agora é institucionalizar o dissenso, por uma ação sustentada em um realismo pragmático, em detrimento das práticas revolucionárias, estas últimas desvalorizadas pela estratégia dos militares, de definir o "golpe de 64" como "revolução", apresentando um deslocamento da significação política da palavra (Fontes, 1996, p. 232). Conforme Fontes, apenas com a reativação dos movimentos sociais no fim da década de 70 é que ocorrerá a revalorização 
tuíram em formas de intervenções políticas dos intelectuais, informadas pelos eventos em curso e motivadas por novos desdobramentos (aberturas) possíveis (Fontes, 1996, p. 52 e Pécaut, 1990, p. 259).

O impacto das formulações acadêmicas, mas conjunturalmente informadas, nas ações e concepções políticas dos atores é inegável tanto quanto os trunfos políticos que a participação em fóruns de debate, como o IEPES, trouxeram para os intelectuais.

O olhar dos oponentes

Líderes e políticos que realmente praticam política na sua essência, na sua pureza, destacam-se em todos os tempos, e André Forster destacou-se num momento importante da vida política brasileira, liderando muitos jovens, mantendo-se ao lado de muitos jovens de todos os partidos de esquerda...Espero que os jovens que nos acompanham, que militam na política tenham o sucesso e a habilidade política de André Forster (João Fischer/PPB).

V. Exa. tenha a absoluta certeza de que não há nenhuma contradição em ver um filho da Arena se manifestar, respeitosamente, para reconhecer o trabalho de um antigo adversário político, André Forster, num escalão bem mais superior ao meu, deu exemplos consolidados, idéias de ações no Rio Grande do Sul, que todos nós reconhecemos (Francisco Appio/PPB).

As passagens de políticos oriundos da Arena e situados em posições políticas opostas às do homenageado, indicam a relevância do reconhecimento da autoridade do oponente no embate político. O que se observa é a afirmação de eventos históricos que impuseram, por meio das lutas dos seus protagonistas, uma carga simbólica da qual nem os oponentes podem esquivar-se.

Assim, devido à importância social e política conquistada por Forster 
em um evento histórico marcante para todos aqueles nele inseridos (o regime militar e a "luta pela democracia"), o mesmo acaba incorporando o capital simbólico acumulado nas e pelas lutas travadas naquele momento. ${ }^{14}$ É ele o referencial de um engajamento ocorrido no momento dos fatos e de uma reivindicação da fidelidade às atitudes adotadas então.

É importante lembrar que os atributos ressaltados na homenagem são resultado de um longo e incessante trabalho de "recuperação da memória" ou de reconstrução efetuada pela memória dos atores políticos envolvidos (entre eles o próprio homenageado). A eficácia deste trabalho é tão marcante que, independentemente das posições políticas, o valor democrático passa a ser patrimônio de protagonistas de uma jornada historicamente situada.

Cabe ainda ressaltar a afirmação de um corte etário que distingue, que classifica e que fornece ao ator-referência uma série de qualificações socialmente reconhecidas e valorizadas, tais como a "pureza na prática política", "liderança" e "habilidade", estas evidenciadas em um "momento importante da vida política brasileira". Observa-se, novamente, a afirmação do evento como produtor de efeitos duráveis e de identificação.

A condição de "jovem", que é afirmada e reafirmada em quase todos os pronunciamentos, é utilizada para informar uma especificidade etária correlacionada a atributos como "disposições", "voluntarismos", "desprendimentos", etc. Cumpre lembrar que a categoria "juventude" adquire diferentes usos e sentidos conforme o espaço de lutas em que ela está inserida. A caracterização feita é indissociável do universo de protestos em que ela foi produzida.

A recepção de um "legado"

14 Vale fazer referência às proposições de Bourdieu (1996): o peso dos diferentes agentes depende de seu capital simbólico, isto é, do reconhecimento, institucionalizado ou não, que recebem de um grupo: a imposição simbólica, esta espécie de eficácia mágica que a ordem ou a palavra de ordem, mas também o discurso ritual ou a simples injunção, até mesmo a ameaça ou o insulto, pretendem exercer, só pode funcionar enquanto tal quando estiverem reunidas condições sociais inteiramente externas à lógica propriamente lingüística do discurso (p. 60). 
Sociologias, Porto Alegre, ano 5, no 10, jul/dez 2003, p. 380-411

André Forster, sem dúvida, é merecedor deste registro histórico. Queremo-nos associar à sua conduta pessoal, à sua disposição de não se afastar de suas convicções políticas, como forma de prestar, hoje, aqui, uma homenagem à sua luta política, contribuiu decisivamente, às vezes a duras penas, para que este País fosse redemocratizado, para que houvesse abertura, para que efetivamente nos livrássemos do processo ditatorial, concentrador e até opressor, que vivemos ao longo de trinta anos (Beto Albuquerque/PSB).

Recordamos a época em que fazíamos campanha na universidade e a influência política que o homenageado exercia sobre as lideranças estudantis da época, entre os quais nos incluímos...André Forster pelo papel relevante que desempenhou contra a ditadura militar e, depois, na luta de todos nós pela consolidação do regime democrático... Tomamos caminhos político-partidários diferentes, mas tenho absoluta convicção de que nos une ao André o laço do objetivo comum pela construção da sociedade que desejávamos construir, aliás, uma sociedade muito diferente da que está aí (Vieira da Cunha/PDT).

As passagens acima corroboram as considerações já feitas, motivadas pelos relatos precedentemente explicitados. No entanto, aqui se expressa um novo elemento, qual seja o da proclamação e reivindicação da herança deixada por Forster.

A localização e a centralidade facultadas ao homem político para a "abertura" e "consolidação democrática", sendo enfatizadas por dois políticos que ingressaram na atividade política posteriormente (final da década de 70), demonstram os resultados dos investimentos empregados pela "geração de André Forster", no sentido de promover e fixar símbolos de iden- 
tificações políticas e ideológicas. Numa arena de diversificação partidária (reorganização do sistema partidário), há a permanência do legado e dos valores anteriormente construídos e constantemente reatualizados, inclusive com o apoio das novas versões oferecidas pelos novos atores.

Desta forma, "associar-se à sua conduta" e "incluir-se entre aqueles influenciados" por Forster, assim como "homenagear a luta política" e estabelecer a equivalência do "objetivo comum" (sociedade diferente), significa partilhar das prerrogativas inerentes àqueles que comungam uma causa vivida como transcendental. Muitas vezes, estes herdeiros são responsáveis pela atualização da causa e pela construção da sua memória, constituindo sentidos para os seus atos e suas posições na esfera política, mediante a organização de uma narrativa e da sua localização nessa narrativa.

Da convivência partilhada num «momento de exceção» e da construção de um repertório de mobilização comum entre os sujeitos envolvidos, seguiu a verificação de uma segunda dimensão de análise. Isto é, as condições comuns (históricas, etárias, ideológicas, etc., mesmo que disputando um espaço diferencial no interior da «juventude» e da «esquerda») e os laços de identificação e exclusão forjados contribuíram para a produção de uma idéia de "pertencimento geracional" reivindicado pelos agentes nas suas referências sobre o passado.

Assim, a categoria "geração" aproxima os personagens, ligando uns aos outros e estes, aos eventos marcantes das suas afirmações no espaço político gaúcho, e delineia os contornos de uma gama de repertórios comuns. Contudo, essa mesma categoria que os vincula e os distingue dos demais políticos comporta um sistema de classificações interno. Classificações como relativas às diferenciações ideológicas entre grupos, à hierarquização entre militantes com experiência prévia e aqueles mais jovens, e às notoriedades advindas das participações em «eventos» (campanhas, cassações, prisões, etc.) quando transformados em trunfos políticos agilizados a partir da construção geracional. 
Sociologias, Porto Alegre, ano 5, no 10, jul/dez 2003, p. 380-411

\section{Referências}

BARROS, M. M. Linz de. Memória e Família. In: Estudos Históricos, Rio de Janeiro, Vértice, v. 2, n. 3, 1989, p. 29-42.

BOURDIEU, Pierre. A juventude é apenas uma palavra. In: BOURDIEU, Pierre. Questões de Sociologia. Rio de Janeiro: Marco Zero, 1983, p. 112-121.

BOURDIEU, Pierre. A Economia das Trocas Lingüísticas. São Paulo: EDUSP, 1996. $188 p$.

DOBRY, Michel. Sociologie des Crises Politiques. Paris: Fondation Nationale des Sciences Politiques, 1992, 319 p.

DROUIN, Vincent. Enquêtes sur les Générations et la Politique (1958-1995). Paris: L'Harmattan, 1995.

FAVRE, Pierre. "De la question sociologique des générations et de la difficulté à la résoudre dans le cas de la France". In: FAVRE, Pierre e CRÊTE, Jean. Générations et Politique. Paris: Economica et PUL, 1996, p. 283-321.

FONTES, Virgínia Maa G. de M. Démocratie et Révolution: Sciences Sociales et pensée politique au Brésil contemporain. Tese de doutorado. Paris: Universidade de Paris X. 1996. 372 p.

GIRARDET, R. Du concept de génération à la notion de contemporanéité. In: Revue d'histoire moderne. 1983, p. 275-288.

HALBWACHS, Maurice. La mémorire collective. Paris: PUF, 1968, 367 p.

HÉLIAS, Yves. Pour une sémiologie politique des monuments aux morts. In. Revue Française de Science Politique, v. 29, n. 4-5, 1979, p. 739-759.

LAMOUNIER, Bolivar (org.). Voto de Desconfiança: eleições e mudança politica no Brasil, 1970 - 1979. Rio de Janeiro: CEBRAP e Vozes,1980, 265 p.

NEVEU, Érik. Sociologie des mouvements sociaux. Paris: La Decouvert, 1996, $168 \mathrm{p}$. 
NORA, Pierre. La Génération. In: NORA, Pierre (org.). Les Lieux de Mémoire. V. 2. Paris: Gallimard, 1997, p. 2975-3015.

PÉCAUT, Daniel. Os intelectuais e a política no Brasil, entre o povo e a nação. São Paulo: Ática, 1990. 335 p.

POLLAK, Michel. Memória, esquecimento, silêncio. In. Estudos Históricos, Rio de Janeiro: Vértice, v. 2, n. 3, 1989, p 3-15.

SAWICKI, Frédéric. Les réseaux du Parti Socialiste. Paris: Belin, 1997, 335 p.

SAWICKI, Frédéric. Vingtième Siècle, Revue D'Histoire, no 22, avril-juin, 1989.

\section{Resumo}

Este artigo trata da temática referente às dinâmicas de construções geracionais e ao trabalho de memória, ativados por determinados agentes sobre um momento histórico específico. Para tanto, propõe-se, num primeiro momento, uma breve discussão bibliográfica sobre as noções de «geração» e «memória», principalmente sobre o potencial heurístico destas. No momento seguinte, o empreendimento recai na análise de um conjunto de narrativas e homenagens centradas na mobilização política da juventude de esquerda do MDB gaúcho na «luta contra a ditadura» (especialmente o exame de um Grande Expediente realizado na Assembléia Legislativa do RS em homenagem póstuma ao sociólogo e líder político André C. Forster). Com estes dois momentos pretende-se discutir o uso operacional de determinadas categorias para a compreensão dos movimentos históricos e dos personagens que os animam.

Palavras-chave: geração, engajamento político, juventude. 